\title{
Reactive airways dysfunction syndrome due to chlorine: sequential bronchial biopsies and functional assessment
}

\author{
C. Lemière*, J-L. Malo*, M. Boutet**
}

Reactive airways dysfunction syndrome due to chlorine: sequential bronchial biopsies and functional assessment. C. Lemière, J-L. Malo, M. Boutet. (CERS Journals Ltd 1997. ABSTRACT: Very little information is available on the acute histopathological bronchial alterations caused by reactive airways dysfunction syndrome (RADS). We had the opportunity to carry out sequential bronchial biopsies in a subject with RADS due to chlorine $(60 \mathrm{~h}, 15$ days, 2 and 5 months after the acute exposure), and also to assess spirometry and bronchial responsiveness to methacholine.

A 36 year old worker in a water-filtration plant (nonsmoker) abruptly inhaled high concentrations of chlorine on September 12, 1994. He experienced immediate nasal and throat burning, retrosternal burning and wheezing, and these symptoms persisted during and after the workshift. Two days later, he complained of retrosternal burning, dyspnoea and wheezing. Inspiratory wheezing was documented. His forced expiratory volume in one second (FEV1) was $66 \%$ of predicted and the provocative concentration of methacholine causing a $20 \%$ fall in FEV1 (PC20) was slightly abnormal $\left(2.5 \mathrm{mg} \cdot \mathrm{mL}^{-1}\right)$. On the following day, the patient underwent bronchial biopsies, which showed almost complete replacement of the epithelium by a fibrinohaemorhagic exsudate. The subject was prescribed inhaled steroids.

Fifteen days after the accident, the PC20 was improved to $6 \mathrm{mg} \cdot \mathrm{mL}^{-1}$. Bronchial biopsies showed considerable epithelial desquamation with an inflammatory exudate and swelling of the subepithelial space. Five weeks after the accident, the PC20 was normal $\left(57 \mathrm{mg} \cdot \mathrm{mL}^{-1}\right)$. Inhaled steroids were stopped. Two months after the accident, the $\mathrm{PC} 20$ deteriorated to $4 \mathrm{mg} \cdot \mathrm{mL}^{-1}$. Biopsies then showed regeneration of the epithelium by basal cells and there was still a pronounced inflammatory infiltrate. Inhaled steroids were restarted. Three and five months later, the PC20 was normal $\left(24 \mathrm{mg} \cdot \mathrm{mL}^{-1}\right)$. Bronchial biopsies showed a greatly improved epithelium and reduction of the inflammatory infiltrate.

This case report shows that reactive airways dysfunction syndrome can cause acute, marked, though partially reversible, histological abnormalities. Inhaled steroids may modulate changes in bronchial responsiveness in this condition. Eur Respir J., 1997; 10: 241-244.

In 1985, BROOKS et al. [1] defined the reactive airways dysfunction syndrome as an asthma-like condition that arises after a single inhalation of miscellaneous irritant agents. Bronchial hyperresponsiveness is the key functional alteration, with airway calibre most often remaining normal. Chlorine is one of the main causal agents, as described in later case reports [2, 3] and a recent review [4]. The time course of functional and histological changes after acute inhalation of irritant agents is not yet well known. The effect of inhaled steroids on bronchial hyperresponsiveness caused by RADS is also unknown. We report the case of a subject who developed RADS after a single high exposure to chlorine. Serial functional assessment was carried out and bronchial biopsies were performed on four occasions $(60 \mathrm{~h}$, 15 days, 2 and 5 months) after acute exposure.

\section{Case report}

A 36 year old male had been employed for $10 \mathrm{yrs}$ in a water-filtration plant. He mixed gaseous chlorine with
*Sacré-Coeur Hospital, Montreal, Québec, Canada. **Laval Hospital, Québec City, Québec, Canada.

Correspondence: J-L. Malo

Dept of Chest Medicine

Hôpital du Sacré-Coeur

5400 West Gouin

Montreal

Canada H4J 1C5

Keywords: Airway obstruction bronchial biopsies

occupational diseases

Received: August 111995

Accepted after revision August 191996

J.L.M. is a senior researcher with the Fonds de la Recherche en Santé du Québec and the Université de Montréal School of Medicine (members of the Centre Québécois d'Excellence en Santé Respiratoire). C.L. is the recipient of a research grant from L'Association Recherche et Partage (Paris, France). sodium chloride, which reacted to produce chlorine dioxide $\left(\mathrm{ClO}_{2}\right)$, and had to mix this with water. Five years earlier, the subject had experienced symptoms of burning throat, cough, dyspnoea and wheezing after chlorine inhalation, but these symptoms had been transient and the subject had not been symptomatic since that event. He was a nonsmoker.

On September 12, 1994, when the subject mixed chlorine dioxide with water, he suddenly experienced a strong odour and nasal, throat and retrosternal burning. A chlorine detector alarm had sounded. He had to leave the room where he worked. After the room had been ventilated, he returned to work. The clinical, functional and bronchoscopic features of the following events are listed in table 1. One hour later, the subject started noticing wheezing, retrosternal burning and headaches. These symptoms worsened in the evening and he could not sleep until 03:00 h. On the following day, he went back to work, and again experienced chest wheezing and retrosternal burning.

He was seen by a physician. The chest radiograph was normal. He was prescribed salbutamol on demand. 


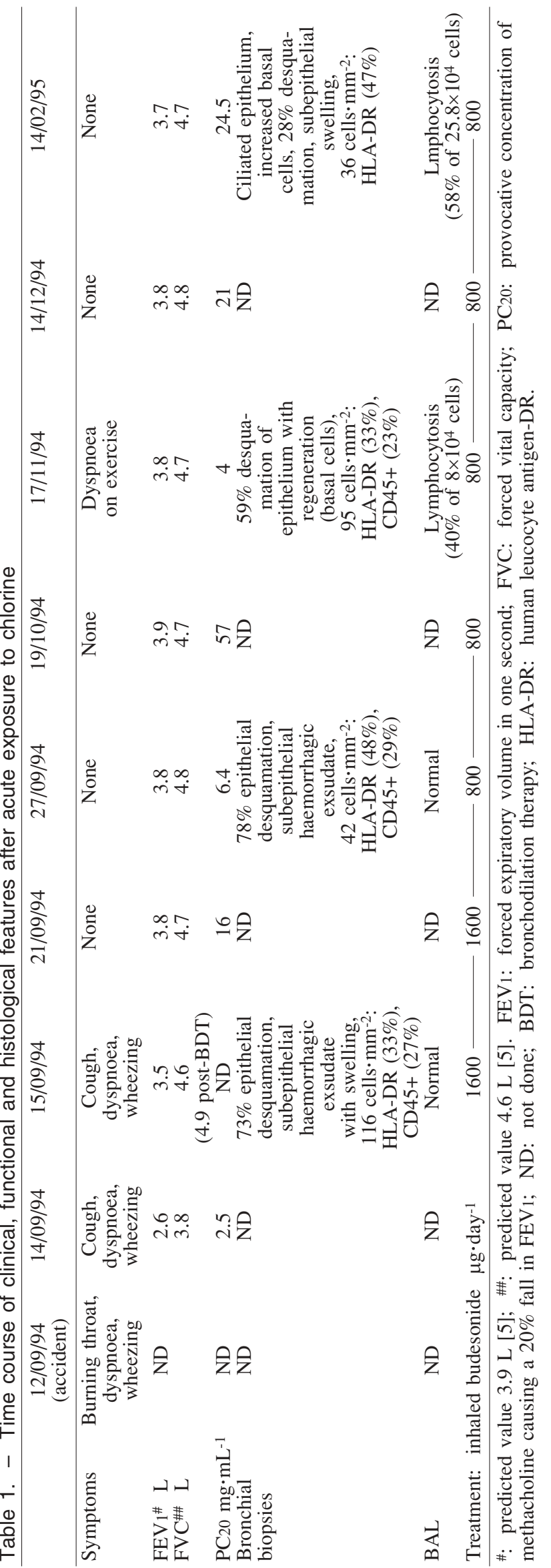

a)

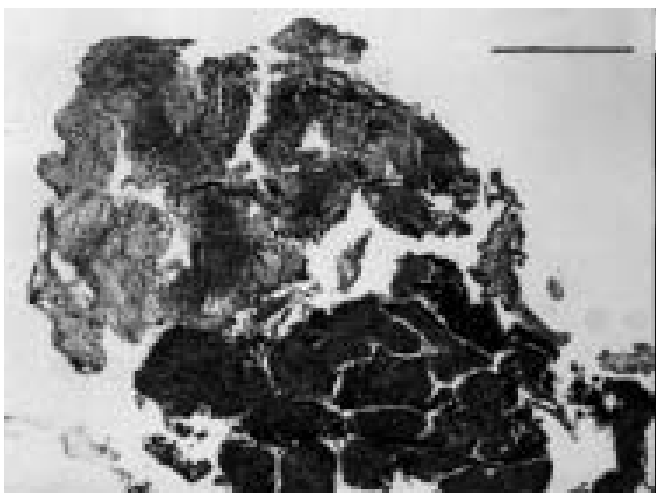

b)

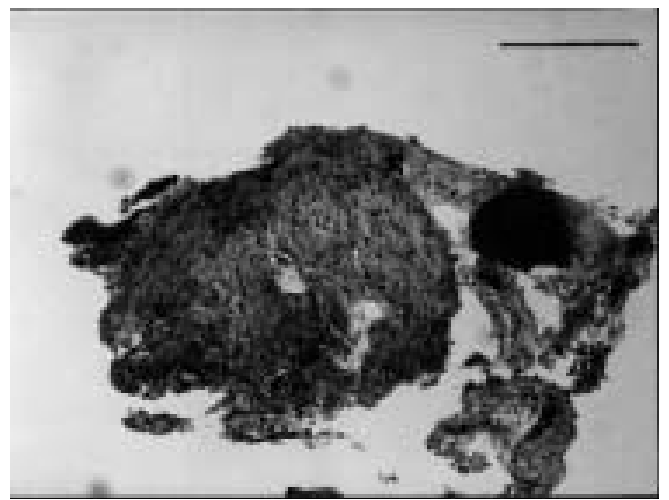

c)

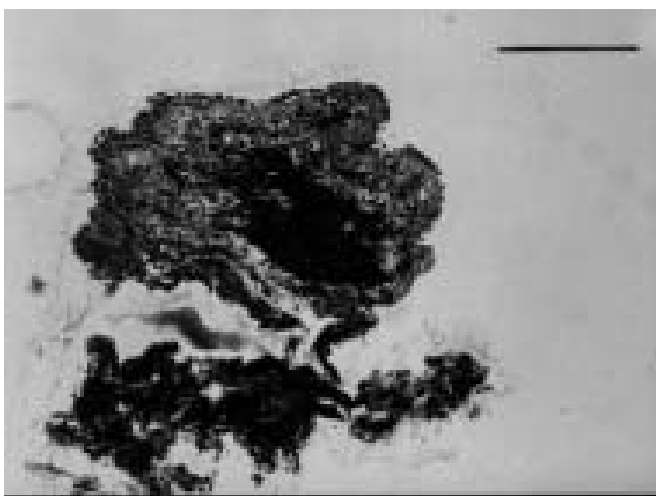

d)

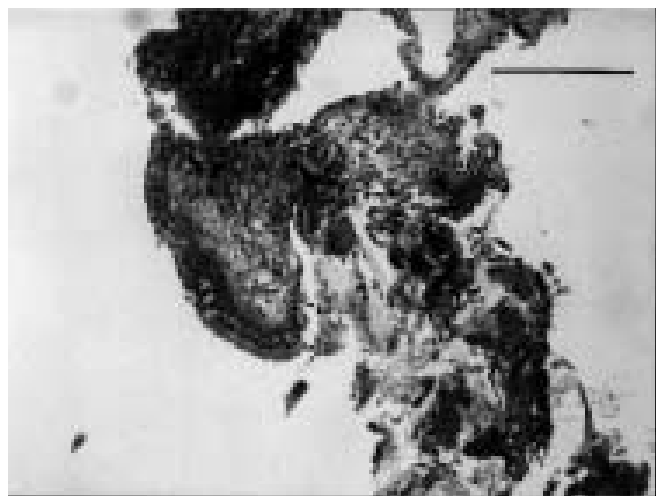

Fig. 1. - a) Almost complete desquamation of the bronchial mucosa (left and upper portion) with fibrinohaemorrhagic deposit (dark pink colour). Inflammatory influx of neutrophils (dark purple spots in the middle and upper portions). Normal smooth muscle (right hand side). (Weigert-Masson stain). b) Almost complete desquamation of surface epithelium. Oedema of the subepithelial zone with inflammatory infiltrate. (Weigert-Masson stain). c) Regeneration of basal cells. No ciliated cells. Oedema of the subepithelial zone with inflammatory infiltrate. (Weigert-Masson stain). d) Ciliated epithelium (left hand side) with increased basal cells. Oedematous subepithelial zone with inflammatory cells. (Weigert-Masson stain). Scale bars $=100 \mu \mathrm{m}$. 
On September 14, the subject was seen by a chest physician, who noticed inspiratory wheezing. Spirometry showed a reduced forced expiratory volume in one second (FEV1) value of $2.6 \mathrm{~L}$ (67\% of predicted value $(3.9$ L) [5]), and forced vital capacity (FVC) $3.8 \mathrm{~L} \mathrm{(83 \%} \mathrm{of}$ predicted value $(4.6 \mathrm{~L})$ [5]). The transfer factor of the lung for carbon monoxide was normal. The provocative concentration of methacholine causing a $20 \%$ fall in FEV1 (PC20) using a standardized procedure [6] (output of nebulizer $\left.=0.14 \mathrm{~mL} \cdot \mathrm{min}^{-1}\right)$ was $2.5 \mathrm{mg} \cdot \mathrm{mL}^{-1}($ mild bronchial hyperresponsiveness).

On September 15, i.e. $60 \mathrm{~h}$ after the acute exposure, a first bronchoscopy was performed. The bronchial mucosa was hyperaemic with mucoid secretions. Features of biopsies and bronchoalveolar lavage (BAL) are shown in table 1 and figure 1a. The subject was then prescribed inhaled steroids (budesonide 1,600 $\mu \mathrm{g}$ daily). He was reassessed on September 21 (Day 9). He was asymptomatic, with no bronchial obstruction, and methacholine challenge showed borderline bronchial hyperresponsiveness (table 1). A second bronchoscopy was scheduled on September 27 (Day 15). Hyperaemia of the bronchial mucosa was less pronounced than 12 days previously. Biopsies and BAL are described in table 1 and figure 1b. The dose of inhaled steroids was reduced to $800 \mu \mathrm{g}$ daily. On October 19 (Day 43), the subject had normal spirometry and the methacholine test no longer showed bronchial hyperresponsiveness. Inhaled steroids were progressively decreased and stopped.

One month later, the subject complained of dyspnoea and retrosternal burning during exercise. Spirometry was normal, but the methacholine test showed mild bronchial hyperresponsiveness. Inhaled steroids were restarted (budesonide $800 \mu \mathrm{g}$ daily). Bronchoscopy was repeated a third time, 2 months after the initial event. The bronchial mucosa was still hyperaemic. The abnormal features of biopsies and BAL are shown in table 1 and figure 1c. One month later, the subject was asymptomatic, and no longer had bronchial hyperresponsiveness. Inhaled steroids were maintained at the same dose. On February 14, 1995 (Day 166), the subject was completely asymptomatic and had normal respiratory function. A last bronchoscopy was performed. Features of bronchial biopsies and BAL are shown in table 1 and figure $1 \mathrm{~d}$.

\section{Discussion}

We report a case of RADS that occurred after acute exposure to chlorine. Although RADS secondary to chlorine has been described by several authors $[3,7,8]$, we report for the first time, to our knowledge, serial measurements of spirometry and bronchial responsiveness combined with histological evaluation on four occasions, shortly after acute exposure to chlorine. The histopathological features are those of acute desquamation of the epithelium, with subepithelial haemorrhage and swelling, inflammatory infiltrates, and regeneration of the epithelium at a later stage (Day 72). Bronchial hyperresponsiveness appeared to be modulated and reversed by the use of inhaled steroids. Similar clinical, functional and histological features were recently described by our group in a subject who suffered RADS induced by exposure to an isocyanate [9].
Few authors $[1,8]$ have reported histological findings of RADS, and these were only documented at least one year after the acute exposure. They showed mild chronic inflammation and focal desquamation of the epithelial layer, as well as bronchial wall thickening. There is no report, to our knowledge, of the histological features shortly after acute exposure to a common causal agent, chlorine. In the various cases described in previous studies $[1,8]$, there was persistent histological damage at least one year after exposure. The subjects also had persistent airway hyperresponsiveness. The two subjects reported by BROOKS et al. [1], each of whom had bronchial biopsies 1 and 3 yrs after exposure, had persistent bronchial obstruction and airway hyperresponsiveness. Among the 15 subjects suffering from RADS studied by GAUTRIN et al. [8], five subjects with bronchial hyperresponsiveness underwent bronchoscopy with bronchial biopsies. These revealed desquamation of the epithelial layer, inflammatory infiltrate and extended fibrosis, which was the main feature. These authors did not perform biopsies in subjects who had returned to a baseline of normal responsiveness.

It is likely that persistent airway hyperresponsiveness is related, in this condition as for asthma, to persistent epithelial damage $[10,11]$, inflammation [12, $13]$, and/or structural changes. It has been shown in asthma that structural changes related to bronchial wall thickness with oedema and inflammation, or in airway smooth muscle can modify airway responsiveness $[14,15]$. The present case also shows that functional integrity does not necessarily mean histological integrity. Indeed, this subject was no longer complaining of respiratory symptoms nor did he have airway hyperresponsiveness or airway obstruction, at a time when bronchial biopsies showed epithelial desquamation, inflammatory infiltrate and swelling of the subepithelial space, and BAL showed lymphocytosis. It is interesting to note that the lymphocytosis, detected at the time of the third and fourth bronchoscopies, only followed the appearance of inflammatory cells detected by immunohistochemistry within the bronchial layer at an earlier stage.

The differential diagnosis of this case includes all types of acute bronchitis, including that caused by viral infection, which shares some histological features (desquamation of epithelium, infiltrate of inflammatory cells) and for which inhaled steroids can also be of benefit. In the present case, the history was, however, directly related to chlorine exposure.

Inhaled steroids could have modulated the course of the disease. Indeed, after the first attempt to stop inhaled steroids, the subject again complained of respiratory symptoms when exposed to nonspecific irritants, and the $\mathrm{PC} 20$ fell from 57 to $4 \mathrm{mg} \cdot \mathrm{mL}^{-1}$. He rapidly recovered after 1 month of inhaled steroid treatment. Inhaled steroids, therefore, seem to be efficacious in RADS, normalizing nonspecific bronchial hyperresponsiveness and improving symptoms. We do not know, however, what the functional course and histological changes would have been without inhaled steroids. The changes that were noted might represent the natural history of the disease, although it appeared that inhaled steroids modulated the course of bronchial responsiveness. Randomized studies on RADS using inhaled steroids versus placebo would be necessary to make a precise evaluation 
of the efficacy of inhaled steroids, and also to determine the optimum dose and duration of treatment after acute exposure. Alternatively, the effect of parenteral or inhaled steroids could be first assessed in animal models of RADS.

In conclusion, this case report shows that reactive airways dysfunction syndrome can cause acute, marked, though partially reversible, histological abnormalities. Inhaled steroids may modulate changes in bronchial responsiveness in this condition.

Acknowledgements: The authors would like to thank $\mathrm{C}$ Leblanc and M. Bélanger for technical support and L. Schubert for reviewing the manuscript.

\section{References}

1. Brooks SM, Weiss MA, Bernstein IL. Reactive airways dysfunction syndrome (RADS): persistent asthma syndrome after high level irritant exposures. Chest 1985; 88: 376-384.

2. Boulet LP. Increases in airway responsiveness following acute exposure to respiratory irritants: reactive airway dysfunction syndrome or occupational asthma? Chest 1988; 94: 476-481.

3. Moore B, Sheman M. Chronic reactive airway disease following acute chlorine gas exposure in an asymptomatic atopic patient. Chest 1991; 100: 855.

4. Das R, Blanc PD. Chlorine gas exposure and the lung: a review. Toxic Ind Health 1993; 9: 439-455.

5. Knudson RJ, Lebowitz MD, Holberg CJ, Burrows B. Changes in the normal maximal expiratory flow-volume curve with growth and aging. Am Rev Respir Dis 1983; 127: 725-734.

6. Cockcroft DW, Killian DN, Mellon JJA, Hargreave FE. Bronchial reactivity to inhaled histamine: a method and clinical survey. Clin Allergy 1977; 7: 235-243.

7. Hasan FM, Geshman A, Fuleihan FJD. Resolution of pulmonary dysfunction following acute chlorine exposure. Arch Environ Health 1983; 38: 76-80.

8. Gautrin D, Boulet LP, Boutet M, et al. Is reactive airways dysfunction syndrome (RADS) a variant of occupational asthma? J Allergy Clin Immunol 1994; 93: $12-22$.

9. Lemière $\mathrm{C}$, Malo JL, Boulet LP, Boutet M. Reactive airways dysfunction syndrome induced by exposure to a mixture containing isocyanate: functional and histopathologic behaviour. Allergy 1996; 51: 262-265.

10. Laitinen LA, Heino M, Laitinen A, Kava T, Haahtela T. Damage of the airway epithelium and bronchial reactivity in patients with asthma. Am Rev Respir Dis 1985; 131: 599-606.

11. Beasley R, Roche WR, Roberts JA, Holgate ST. Cellular events in the bronchi in mild asthma and after bronchial provocation. Am Rev Respir Dis 1989; 139: 806-817.

12. Bousquet J, Chanez P, Lacoste J-Y, et al. Eosinophilic inflammation in asthma. N Engl J Med 1990; 323: 1033-1039.

13. Pin I, Godard P. Mécanismes de l'hyperréactivité bronchique: rôle de l'inflammation des voies aériennes et de l'atopie. Rev Mal Respir 1994; 11: 111-122.

14. Moreno RH, Hogg JC, Paré PD. Mechanics of airway narrowing. Am Rev Respir Dis 1986; 133: 1171-1180.

15. Marthan R, Stephens NL. Mécanismes de l'hypérreactivité bronchique: rôle du muscle lisse. Rev Mal Respir 1994; 11: 149-159. 